\title{
Progresso de doenças fúngicas e correlação com variáveis climáticas em mamoeiro
}

\author{
Márcio Shiguero Suzuki ${ }^{1}$, Laércio Zambolim² ${ }^{2}$ José Ricardo Liberato $^{2}$
}

${ }^{1}$ Caliman Agrícola S.A., Rod. BR 101, KM 111, CEP 29.900-970, Linhares, ES; ${ }^{2}$ Departamento de Fitopatologia, Universidade e Federal de Viçosa, CEP 36.570-000, Viçosa, MG.

Autor para correspondência: Laércio Zambolim

Data de chegada: 09/02/2005. Aceito para publicação em: 08/11/2006.

\section{RESUMO}

Suzuki, M. S.; Zambolim, L.\& Liberato; J. R. Progresso de doenças fúngicas e correlação com variávies climáticas em mamoeiro. Summa Phytopathologica, v.33, n.2, p.167-177, 2007.

Avaliou-se o progresso de doenças fúngicas do mamoeiro e os efeitos dos fatores climáticos em três áreas experimentais: 1- área de produção de mamão conduzida no sistema convencional, que recebeu irrigação por gotejamento; 2- área de produção de mamão conduzida no sistema convencional, que recebeu irrigação por aspersão; 3- área de produção de mamão cultivada no sistema orgânico, com irrigação por microaspersão. $\mathrm{Na}$ área 1 foram avaliados três sistemas diferentes de condução: 1) sem a aplicação de fungicidas e sem sanitização das plantas (testemunha sem sanitização); 2) sem a aplicação de fungicidas e com sanitização das plantas (testemunha com sanitização); e 3) com a aplicação de fungicidas para o controle de doenças foliares e sem sanitização (padrão do produtor). Em cada sistema de condução foram demarcadas quatro parcelas (repetições) com 20 plantas, sendo 10 plantas consideradas úteis. Foram avaliadas a incidência e a severidade da mancha-de-ascoquita, pintapreta e do oídio como doenças foliares. Nos frutos, após a colheita foram avaliadas as incidências da antracnose, mancha-chocolate e podridão-peduncular. As epidemias da mancha-de-ascoquita ocorrem em temperaturas variando de $15{ }^{\circ} \mathrm{C}$ a $20{ }^{\circ} \mathrm{C}$; para a pinta-preta as condições favoráveis ao desenvolvimento de epidemias foi temperatura variando de $25{ }^{\circ} \mathrm{C}$ a $30{ }^{\circ} \mathrm{C}$ e umidade relativa variando de $80 \%$ a $100 \%$, sendo o pico da intensidade da doença ocorre entre os meses de novembro a março. Para o ó́dio, a faixa de temperatura que favoreceu a doença foi $15{ }^{\circ} \mathrm{C}$ a $20{ }^{\circ} \mathrm{C}$ e umidade relativa de 60 a $70 \%$. Em relação às podridões que incidiram nos frutos, observou-se que não houve relação entre a incidência da podridão-peduncular e a precipitação pluvial acumulada, 15 dias antes da avaliação ou no período de desenvolvimento do fruto $(\mathrm{r}$ $<0,21)$. A incidência da antracnose e da mancha-chocolate não se correlacionaram com as condições climáticas. Na área Santa Terezinha 10, a mancha-de-ascochyta foi constatada em todas as épocas de avaliação, tendo severidade máxima na data juliana 155 aos 250 dias e mínima dos 20 aos 80 dias; a pinta-preta progrediu na data 326 aos 70 dias com severidade máxima na data 336 dias, e o oidio progrediu em duas épocas distintas sendo uma na data 330 aos 80 dias e a outra na data 240 aos 320 dias com o máximo na data 240 a 250 dias. A incidência da podridão dos frutos em pós-colheita foi detectada no armazenamento, quando os frutos foram colhidos nas datas de 140 aos 320 dias, sendo alta até a data 220; a partir daí decresceu até a data 320 . O tratamento padrão praticado pelo produtor diferiu significativamente dos tratamentos envolvendo práticas culturais com e sem sanitização, excetuando a podridão peduncular onde o tratamento padrão igualou-se ao tratamento com sanitização. Os tratamentos culturais com e sem sanitização não diferiram entre si. Comparando-se os tratamentos com sanitização e sem sanitização para podridão peduncular houve ganhos de $24 \%$ e $9 \%$, para as datas julianas 170 e 210 , respectivamente; para a antracnose houve ganhos de $13 \%$ e $55 \%$, para as datas julianas 160 e 230 , respectivamente e para a mancha-chocolate $30 \%$ e $9 \%$, para as datas julianas 170 e 210 , respectivamente. O progresso das doenças nas áreas de plantio do curral e Bitchisner foram quase idênticos com relação à incidência de folhas doentes total; a severidade máxima da mancha-deascoquita atingiu $20 \%$ na área do curral e $10 \%$ na área Bitchisner, entre as datas 110 e 320 . A pinta-preta foi muito severa na lavoura do curral e de baixa severidade na lavoura Bitchisner. O oidio foi detectado nas duas lavouras nas datas 230 aos 320 , com maior severidade na lavoura do curral onde predomina a irrigação por aspersão. Obtêve-se severidade do Oidio máxima de 45 e $65 \%$ nas lavouras do curral e Bitchisner, respectivamente. Em se tratando da podridão dos frutos do mamoeiro, a incidência foi maior nas plantas da localidade do curral do que Bitchisner devido ao método de irrigação por aspersão.

Palavras-chave adicionais: Carica papaya, Colletotrichum gloeosporioides, Asperisporium caricae, Ovulariopsis papayae, Phoma caricapapayae.

\footnotetext{
ABSTRACT

Suzuki, M. S.;Zambolim, L. \& Liberato, J. R. Progress of fungal diseases and correlation with climatic variables in papaya. Summa Phytopathologica, v.33, n.2, p.167-177, 2007.

The effect of climatic conditions on progress of fungal diseases of papaya were evaluated in three experimental areas in Linhares, State of Espirito Santo, Brazil. First area was carried out using traditional system and was drip irrigated; second area was also carried out using traditional system, but it was overhead irrigated, and third area was carried out using organic system with micro spray. It was evaluated three different systems

of cultural control in the first area: 1- papaya plants not sprayed with fungicides with any leaf removal (check treatment without sanitation); 2- papaya plants not sprayed with fungicides with leaf removal (check treatment with leaf removal), and 3-papaya plants sprayed with fungicides without leaf removal (grower treatment). Each system received four plots with 20 plants. Evaluation was done in 10 plants in the center
} 
of plots. Incidence and severity of Ascochyta leaf spot, black spot and powdery mildew were evaluated on leaves. It was evaluated the incidence and stem end rot of fruits. Epidemics of Ascochyta leaf spot are favoured by temperatures ranging from $15{ }^{\circ} \mathrm{C}$ to $20{ }^{\circ} \mathrm{C}$. Epidemic of black spot occurred when temperature ranged from $25{ }^{\circ} \mathrm{C}$ to $30{ }^{\circ} \mathrm{C}$ with relative humidity ranging from 80 to $100 \%$, from november to march. Powdery mildew development was favored by temperatures from $15{ }^{\circ} \mathrm{C}$ to $20{ }^{\circ} \mathrm{C}$ and relative humidity from $60 \%$ to $70 \%$. It was not observed any relation between incidence of stem end rot of papaya and acumulated rain 15 days before the evaluation ( $\mathrm{r}$ less than 0.21 ). Incidence of fruit rot diseases caused by anthracnose and chocolate spot did not correlate with weather conditions. Ascochyta leaf spot was detected in all the evaluation data with maximum severity from the juliana date 155 to 250 and minimum from 20 to 80 ; the black spot increased from date juliana 326 to 70 with maximum disease severity on the date 336 ; powdery mildew increased in two distinct times: one from the date 330 to 80 and another form the date 240 to 320 with maximum severity on the date from 240 to 250 . Fruit rot was detected in stored papaya when they were harvested on the dates from 140 to 320 . The pattern treatment employed by the growers differed significantly from the treatments involving cultural practices such as sanitization and no sanitization, with the exception for stem end rot, where the grower pattern treatment did not differ from the treatment with sanitization. The cultural treatments with sanitization did not differ from the treatment without sanitization. However for stem end rot, treatment with sanitization increased $24 \%$ and $9 \%$ the number of commercial fruits for the juliana dates 170 and 210 , respectively over the treatment without sanitization; for anthracnose, $13 \%$ and $55 \%$, for the juliana dates 160 and 230 , respectively and for the chocolate fruit spot $30 \%$ and $9 \%$, for the juliana dates 170 e 210 , respectively.

Total diseased progess curves in the areas called curral and Bitchisner were almost identical; the maximum severity of Ascochyta leaf spot was $20 \%$ in the curral and $10 \%$ in Bitchisner, from the dates 110 e 320 . Black spot was more severe in the curral than in Bitchisner. Powdery mildew was detected on the plants from curral and Bitchisner from dates 230 aos 320 with higher severity on the plants of curral where the plants are irrigated with central pivot. Maximum disease severity of 45 and 65 $\%$ were detected on papaya areas from curral and Bitchisner, respectively. The incidence of papaya black spot was higher on the curral area than on the plants form Bitchisner due to the method of irrigation.

Additional keywords: Carica papaya, Colletotrichum gloeosporioides, Asperisporium caricae, Ovulariopsis papayae, Phoma carica-papayae.

O mamoeiro é uma planta originária das regiões tropicais e subtropicais da América (3). A espécie Carica papaya L. predomina em cultivos comerciais, estando hoje difundida em regiões que apresentam clima tropical, pluviosidade elevada, solos férteis e bem drenados (19). Os cultivares mais plantados no Brasil são classificados em dois grupos: Formosa e Solo, ambos destinados à comercialização tanto no mercado interno quanto no externo.

O mamoeiro pode ser afetado por diversas doenças, que constituem o principal fator limitante da cultura, exigindo medidas adequadas de controle, sem as quais podem ocorrer grandes danos na produção e na comercialização (22). Os níveis de incidência e severidade são usualmente tão altos que o controle das doenças é imprescindível para se obter produções rentáveis e aceitáveis pelo mercado. Entre as doenças destacam-se a pinta-preta ou varíola cujo agente causal é Asperisporium caricae (Speg.) Maubl. É considerada a principal doença fúngica foliar, exigindo manejo contínuo, pois possui potencial para causar danos na ausência de controle, uma vez que a doença pode incidir também nos frutos, podendo torná-los inadequados para o comércio $(5,22)$. Plantas muito afetadas podem perder de 50 a $60 \%$ de suas folhas maduras em um período de dois a três meses (17); a incidência da doença em frutos pode atingir quase $100 \%$ (13). A mancha-de-ascoquita causada pelo fungo Ascochyta carica-papayae (Tarr.), também pode infectar folhas, causando desfolha, e frutos, causando podridão-peduncular (1). O oídio, causado por Ovulariopsis papayae Beijl., embora ocorra no Norte do Espírito Santo, não existem relatos de grandes danos (24).

No caso dos frutos, além da pinta-preta, as doenças de pós-colheita, principalmente a antracnose, a mancha-chocolate e a podridãopeduncular são responsáveis por maiores danos. A antracnose e a mancha-chocolate tem como agente etiológico Colletotrichum gloeosporioides (Penz.) Penz. \& Sacc. in Penz. $(1,10)$. A antracnose é considerada a principal e mais comum doença do mamão na póscolheita no Brasil $(6,24)$. O agente causal da antracnose e da manchachocolate infecta frutos imaturos ainda no campo e permanece sob a forma de infecção quiescente; os sintomas da doença manifesta-se sob a forma de lesões necróticas somente na fase pós-colheita, durante o amadurecimento (9). As podridões pedunculares ocorrem quando a região do pedúnculo é afetada e nela ocorre o sintoma da podridão, e são atribuídas a fungos dos gêneros Colletotrichum, Phomopsis, Fusarium e Phoma, entre outros (1). A doença ocorre quando esses fungos invadem o fruto, após a colheita, através do pedúnculo cortado. Já foi constatada incidência de 68,5 a 100\% de antracnose e podridãopeduncular, respectivamente, em frutos após a colheita $(15,17)$, quando na ausência de quaisquer medidas de controle. Essas doenças são as causas principais danos durante o armazenamento e transporte do fruto, principalmente quando destinado à exportação $(1,14,24)$.

Apesar da importância das doenças fúngicas para o mamoeiro, poucos estudos foram realizados visando ao conhecimento acerca do progresso dessas doenças no Brasil, sendo raros os estudos com informações seguras sobre o efeito dos fatores climáticos que atuam durante o progresso de epidemias dessas doenças. Na região norte do Espírito Santo, a incidência da pinta-preta e da antracnose ocorre nos meses mais quentes do ano (outubro a março) (17,25). A obtenção de informações sobre os efeitos dos fatores climáticos sobre as doenças é imprescindível para recomendar o controle racional destas. São raros os estudos sobre os efeitos de tratos culturais - como a remoção de folhas mortas e senescentes, visando desfavorecer o progresso de epidemias de doenças do mamoeiro - quantificando seus efeitos no desenvolvimento das epidemias das doenças em condições brasileiras. Como a redução de inóculo pela sanitização é considerada a estratégia ideal para o controle de doenças em regiões tropicais (4), essas informações são fundamentais para determinar e recomendar métodos de manejo das doenças visando reduzir os danos causados por doenças fúngicas.

\section{MATERIAL E MÉTODOS}

\section{Localização}

O experimento foi conduzido em três diferentes áreas de cultivo comercial de mamoeiros cv. Sunrise Golden, localizadas na Empresa Caliman Agrícola S/A, no município de Linhares, Estado do Espírito Santo, a $21 \mathrm{~m}$ de altitude. A região esta localizada na latitude de $19^{\circ} 15^{\prime}$ e longitude de $40^{\circ} 10$ ' com precipitação pluvial média anual de 1.100 $\mathrm{mm}$, temperatura média das máximas de $30,7^{\circ} \mathrm{C}$ a $34^{\circ} \mathrm{C}$ e temperatura média das mínimas de $15,8^{\circ} \mathrm{C}$ a $18,0^{\circ} \mathrm{C}$. As lavouras foram instaladas 
em um solo classificado como Podzólico amarelo com textura fina, fraco em fertilidade. Os mamoeiros foram plantados em agosto/ setembro de 2000, em espaçamento de 3,60 x 1,40 m, em fileiras simples, sendo utilizada a cultivar Golden, suscetível às doenças foliares e as podridões dos frutos.

\section{Delineamento experimental}

As três áreas experimentais foram implantadas em delineamento experimental em blocos ao acaso, com quatro repetições, tendo cada repetição 20 plantas, sendo consideradas úteis as 10 plantas centrais. Duas linhas de plantas de cada lado, serviram como bordadura entre os blocos.

\section{Área 1}

A área 1 foi instalada na Fazenda Santa Terezinha, no talhão de número 10 , sendo codificada como ST 10. A lavoura foi conduzida no sistema convencional com irrigação por gotejamento. Empregou-se uma lâmina d'água de $8,0 \mathrm{~mm}$ no verão e de $6,0 \mathrm{~mm}$ no inverno. Nesta área, foram avaliados três sistemas diferentes de condução quanto ao seu efeito no progresso de epidemias de doenças fúngicas do mamoeiro: 1) sem pulverizações e sem sanitização (testemunha sem sanitização), 2) sem pulverização e com sanitização (testemunha com sanitização) e 3) com pulverização convencional e sem sanitização (padrão do produtor).

As pulverizações foram realizadas nas datas julianas 306, 340, 362 de 2000; e 12, 25, 43, 46, 64, 79, 102, 124, 131, 140, 158, 173, $180,219,245,258,270$ e 281 de 2001, fazendo-se rodízio de fungicidas. Cerca de quatro meses após o transplantio, em novembro de 2000, iniciaram-se as avaliações de doenças fúngicas foliares. As avaliações foram realizadas nas datas julianas 328, 342 e 355 de 2000; e $09,22,36,52,64,78,93,106,120,134,148,159,177,187,211$, 233, 246, 260, 272, 288, 302 e 331 de 2001.

Para a avaliação de doenças em frutos, coletaram-se frutos nas parcelas consideradas testemunhas com e sem sanitização, nas datas julianas 137, 151, 166, 180, 192, 204, 221, 236, 247, 269, 283, 316 e 332 de 2001. Nas parcelas consideradas padrão do produtor, coletaram-se os frutos na datas julianas 134, 149, 177, 191, 220, 247, 268,283 e 317 de 2001 .

\section{Área 2}

A área 2 foi instalada na fazenda Lagoa do Macuco, no talhão denominado curral. A lavoura curral foi conduzida no sistema convencional do produtor com irrigação por aspersão. Empregou-se uma lâmina d'água de 8,0 mm no verão e de 6,0 mm no inverno.

Cerca de quatro meses após o transplantio, em novembro de 2000, iniciaram-se as avaliações de doenças fúngicas foliares. As avaliações foram realizadas nas datas julianas 328, 342 e 355 de 2000; e 9, 22, 36, $52,64,78,93,106,120,134,148,159,177,187,211,233,246,260$, $272,288,302$ e 331 de 2001. Para a avaliação de doenças em frutos, coletaram-se frutos nas datas julianas 135, 149, 157, 176, 190, 218, 232, 246, 272, 281 e 316 de 2001.

A lavoura recebeu pulverizações com fungicidas visando ao controle de doenças fúngicas da parte aérea. As pulverizações foram realizadas nas datas julianas $321,329,334$ e 350 de 2000; e 10, 38,59, 80, 92, $100,106,122,137,152,167,188,199,230,248,263,276,288$ e 315 de 2001 .

\section{Área 3}

A área experimental foi instalada na fazenda Lagoa do Macuco, no talhão denominado Bitchisner e foi conduzida no sistema orgânico com irrigação por microaspersão.

Nesta área, as avaliações iniciaram-se no mês de abril de 2001, cerca de oito meses após o transplantio, nas datas julianas 108, 123 , $136,150,167,177,193,212,239,248,265,275,293,304,318$; e 333 de 2001. Para a avaliação de frutos, realizaram-se as coletas nas datas julianas 221, 236, 250, 268, 283; e 316 de 2001.

\section{Avaliação das doenças}

As avaliações tanto da incidência quanto da severidade das doenças foram realizadas em intervalos variando de 14 a 15 dias. Foram avaliadas a incidência geral de doenças fúngicas e a severidade de mancha-deascoquita, pinta-preta e oídio em cinco plantas ao acaso por parcela. $\mathrm{Na}$ avaliação da incidência foram consideradas as folhas cujo lóbulo central se apresentava com comprimento igual ou inferior ao comprimento de seu pecíolo. A severidade foi avaliada em cinco folhas, em média, do terço inferior de cada uma das cinco plantas, sendo desconsideradas as folhas com amarelecimento em mais de $75 \%$ do limbo foliar. A severidade da pinta-preta foi estimada com o uso da seguinte escala de notas (15): 0 (ausência de sintomas), 1 (>0 a 3\%), 2 (>3\% a $6 \%$ ), 3 (>6 a 12\%), 4 (>12 a 25\%) e 5 (de 25 a $50 \%$ da área foliar coberta com sintomas). Para estimar a severidade da mancha-deascoquita e do oídio, utilizou-se chave descritiva com os seguintes valores de doença: 0 (ausência de sintomas), 1 ( $>0$ a 5\%), 2 ( $>5$ a $10 \%), 3$ (>10 a $15 \%$ ) e assim sucessivamente, com intervalos de $5 \%$, até a nota 13 ( $>60 \%$ da área foliar coberta com sintomas). No caso da mancha-de-ascoquita, considerou-se área afetada somente a área necrótica. Análises de correlação foram feitas entre a severidade da mancha-de-ascochyta, pinta-preta e oidio com a temperatura e umidade relativa.

Para a avaliação da incidência da antracnose, mancha-chocolate e podridão-peduncular, coletaram-se dez frutos por parcela, nos estádios de maturação (índice de cor da casca) 1 (de 5 a 15\%), 2 (>15 a 25\%) e 3 (>25 a 45\% de área de casca com coloração amarela), segundo a escala utilizada pelos exportadores (21). A coleta de frutos no campo foi feita duas vezes por semana. Os frutos coletados foram acondicionados em caixas de plástico forradas com plástico-bolha e encaminhados para o Laboratório de Controle de Qualidade Póscolheita da Caliman Agrícola S/A, em Linhares, Espírito Santo. Os frutos de cada parcela foram colocados em prateleiras e mantidos no ambiente com temperatura variado de 22 a $34^{\circ} \mathrm{C}$ e umidade relativa de 55 a $70 \%$. Sete dias após a colheita, avaliou-se a incidência das doenças nos frutos. Análise da variância foi realizada entre os tratamentos padrão do produtor e as práticas culturais remoção de folhas senescentes e doentes denominada de sanitização e ausência de remoção de folhas senescentes em duas datas julianas. As datas julianas escolhidas para análise estatística, foram aquelas onde a incidência de podridão dos frutos foram máximas, considerando as diversas datas de coleta de frutos para análise. As comparações das médias foram realizadas pelo teste de Tukey a $5 \%$.

Avaliou-se também a correlação entre a precipitação pluvial, acumulada nos 15 e 150 dias anteriores à colheita, devido ao fato de, esse ser o espaço de tempo médio entre a antese e a colheita (7, 20, 26).

\section{Dados climáticos}

Para se avaliar a influência dos fatores climáticos sobre as epidemias de doenças fúngicas foram coletados dados meteorológicos com o uso de estações meteorológicas automatizadas, modelo MRC 300 da Metos $^{\mathrm{TM}}$, localizadas no centro das áreas experimentais. O sensor de molhamento foliar foi colocado preso em um pecíolo de folha, no 
terço médio da copa de uma planta, sendo mudado de posição à medida que a planta crescia. Os dados climáticos foram coletados diariamente, entre agosto de 2000 a novembro de 2001. Obtiveram-se as variáveis climáticas de temperatura máxima, temperatura média, temperatura mínima, umidade relativa do ar, molhamento foliar e precipitação.

\section{RESULTADO E DISCUSSÃO}

Não foi possível estabelecer relação entre epidemias da manchade-ascoquita com fatores climáticos específicos. No caso da área 1 (testemunhas com e sem sanitização em Santa Terezinha 10), houve correlação significativa entre a ocorrência da doença com temperaturas variando de 15 a $20^{\circ} \mathrm{C}(\mathrm{r}=0,54,0,50$ e 0,84 , para a testemunha sem sanitização, testemunha com sanitização em Santa Terezinha 10, respectivamente). Nas demais áreas, a correlação não foi significativa para todas as faixas de temperatura estudadas $(\mathrm{r}<0,06)$. A manchade-ascoquita pode ser considerada endêmica na região, pois foi constatada em $100 \%$ das plantas e em todas as épocas do ano, ocorrendo com severidade de 3 a 41\%. Observações realizadas tanto na área experimental quanto nos diversos pomares da empresa Caliman Agrícola constatou-se a doença em maior ou em menor intensidade durante todo o ano. O comportamento da mancha-de-ascoquita em relação à umidade relativa apresentou-se sem consistência, não permitindo conclusão sobre a faixa de maior predisposição para a ocorrência da doença. Esse comportamento errático talvez se deva à presença de ventos litorâneos nos locais, durante todo o ano, podendo ser um fator de predisposição para essa doença. O vento ao movimentar as folhas causa ferimentos, condição necessária para que ocorra infecção pelo patógeno (19).

Em se tratando da pinta-preta, nas áreas em estudo foi possível observar a sua ocorrência entre os meses de novembro e março, sendo severa em regiões com alta umidade relativa e em períodos chuvosos, como os observados nos meses citados (Figuras 1,2, 4 e 5). A faixa de temperatura que apresentou correlação significativa com a ocorrência da doença foi a de 25 a $30{ }^{\circ} \mathrm{C}$, com r de 0,$36 ; 0,62 ; 0,68 ; 0,66$; e 0,93 , para Santa Terezinha 10, testemunha com sanitização, sem sanitização, curral e Bitchisner, respectivamente. Houve correlação entre a umidade relativa na faixa de 80 a $100 \%$ com o desenvolvimento da pinta-preta. Geralmente, no Norte do Espírito Santo, as lavouras novas de mamão entram em produção durante os meses de novembro a março coincidindo com períodos chuvosos e, como os pomares mais novos são os mais suscetíveis seria esse o motivo da observação de epidemias durante essa época do ano. A pinta-preta raramente ocorre em pomares mais velhos e bem conduzidos. Além disso, a colheita dos frutos sendo realizada duas a três vezes por semana, quando o índice de cor da casca for um ( 5 a $15 \%$ de maturação), contribui também para redução da doença no campo.

O método de irrigação por aspersão aumentou a intensidade da
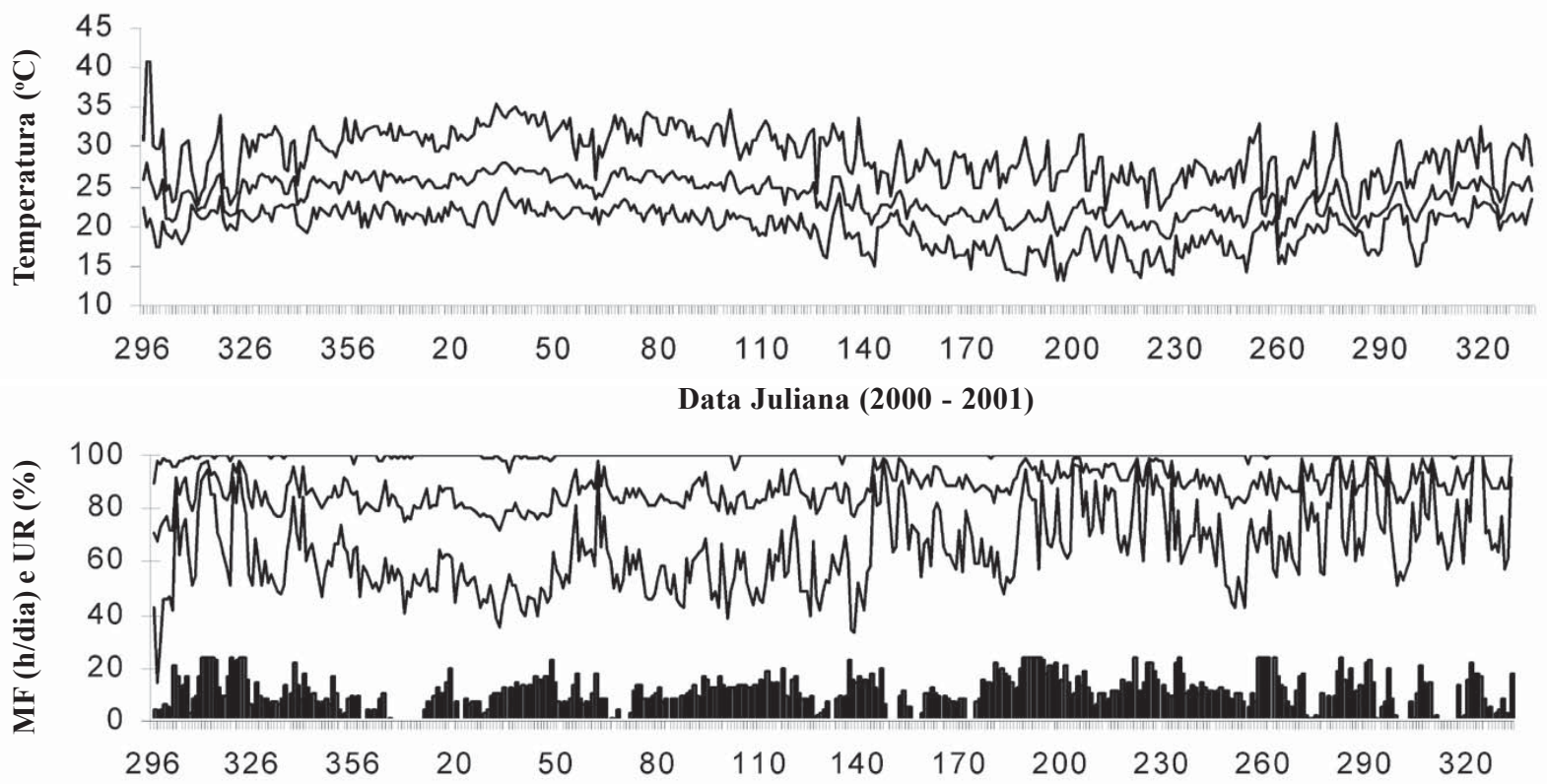

Data Juliana (2000 - 2001)

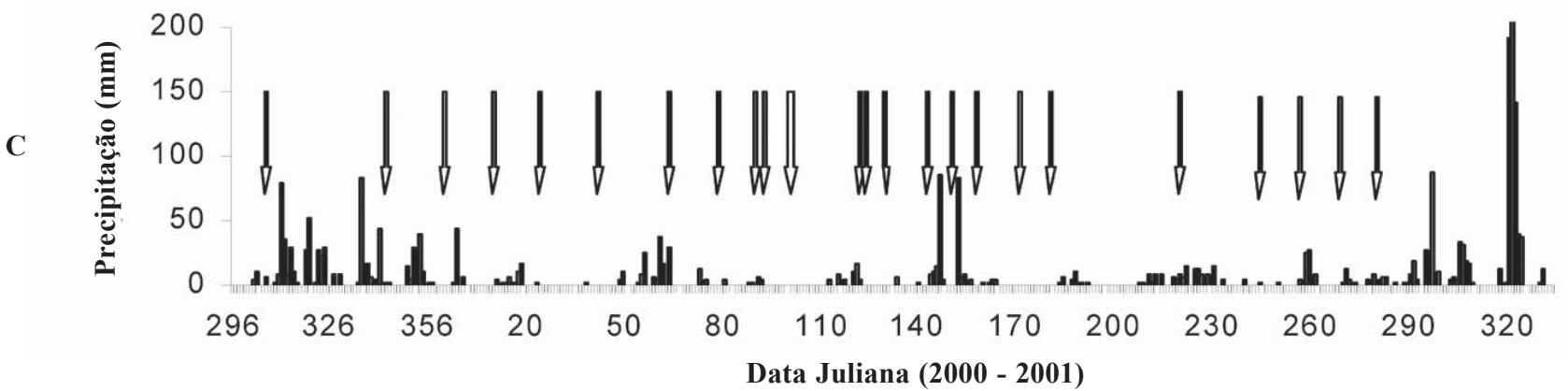

Figura 1 - Dados meteorológicos da Fazenda Santa Terezinha. A) Temperaturas máxima, média e mínima; B) horas com molhamento foliar (MF) barras -, e umidade relativa do ar (UR) - linhas; C) precipitação - as setas indicam os dias das pulverizações com fungicidas na área padrão do produtor. 


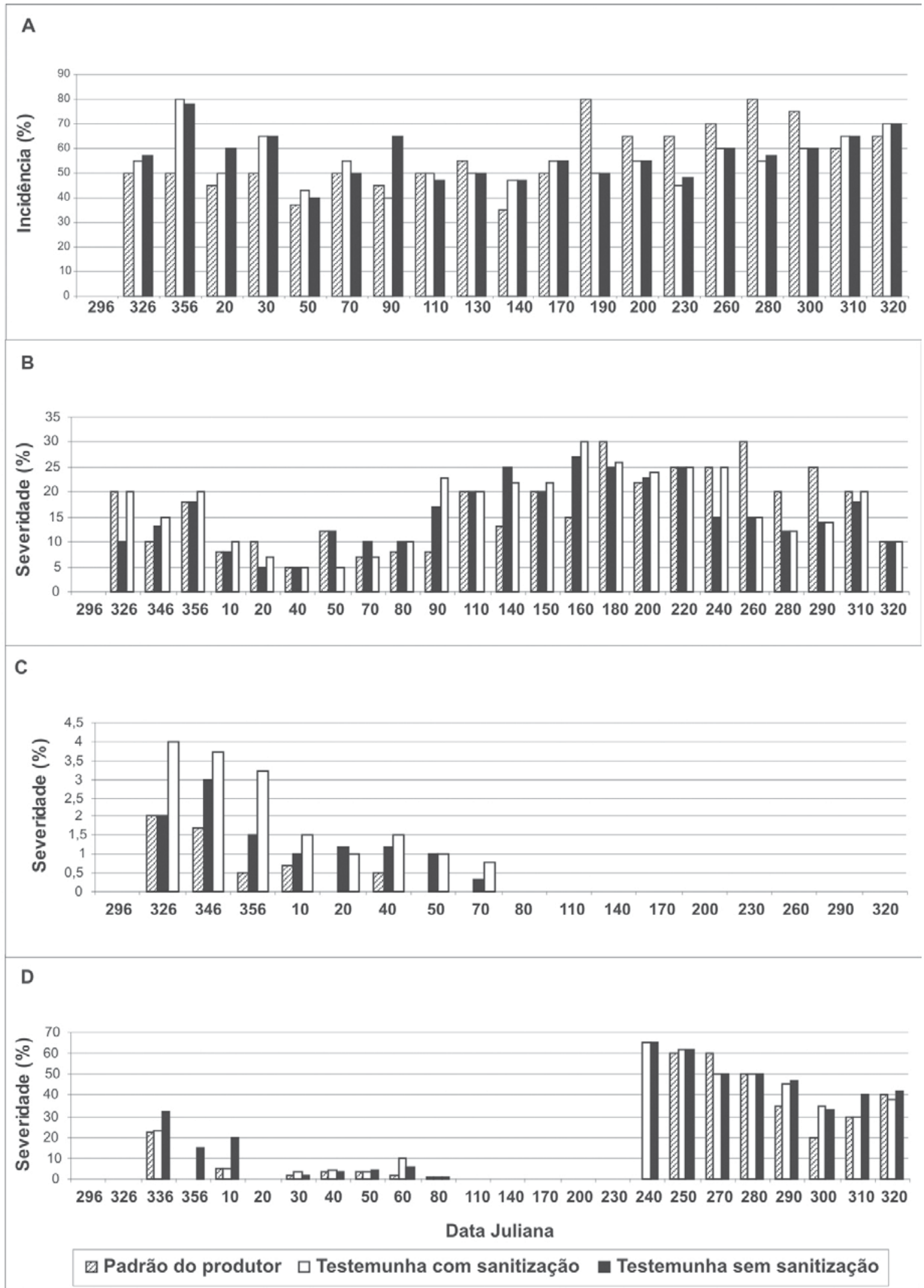

Figura 2 - Incidência de folhas doentes (A) e severidade de mancha-de-ascoquita (B), pinta-preta (C) e oídio (D) detectadas na Área 1 (ST 10), nos diferentes sistemas de condução da cultura do mamoeiro. 


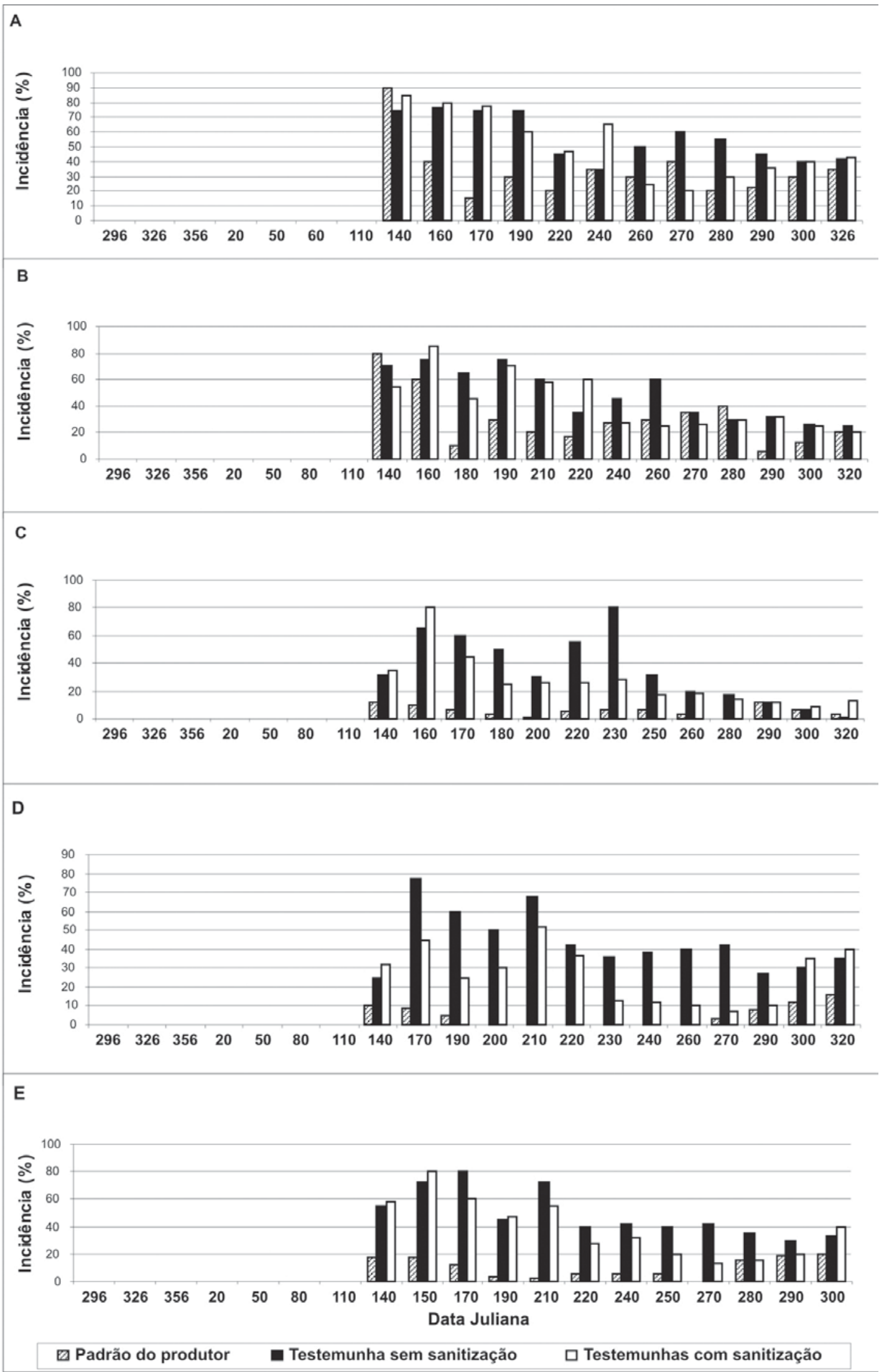

Figura 3 - Incidência das principais doenças de frutos detectadas na Área 1 (ST 10), nos diferentes sistemas de condução da cultura do mamoeiro. (A-Frutos doentes totais; B-Podridão peduncular; C-Antracnose; D-Mancha chocolate; EAntracnose e ou Mancha chocolate). 

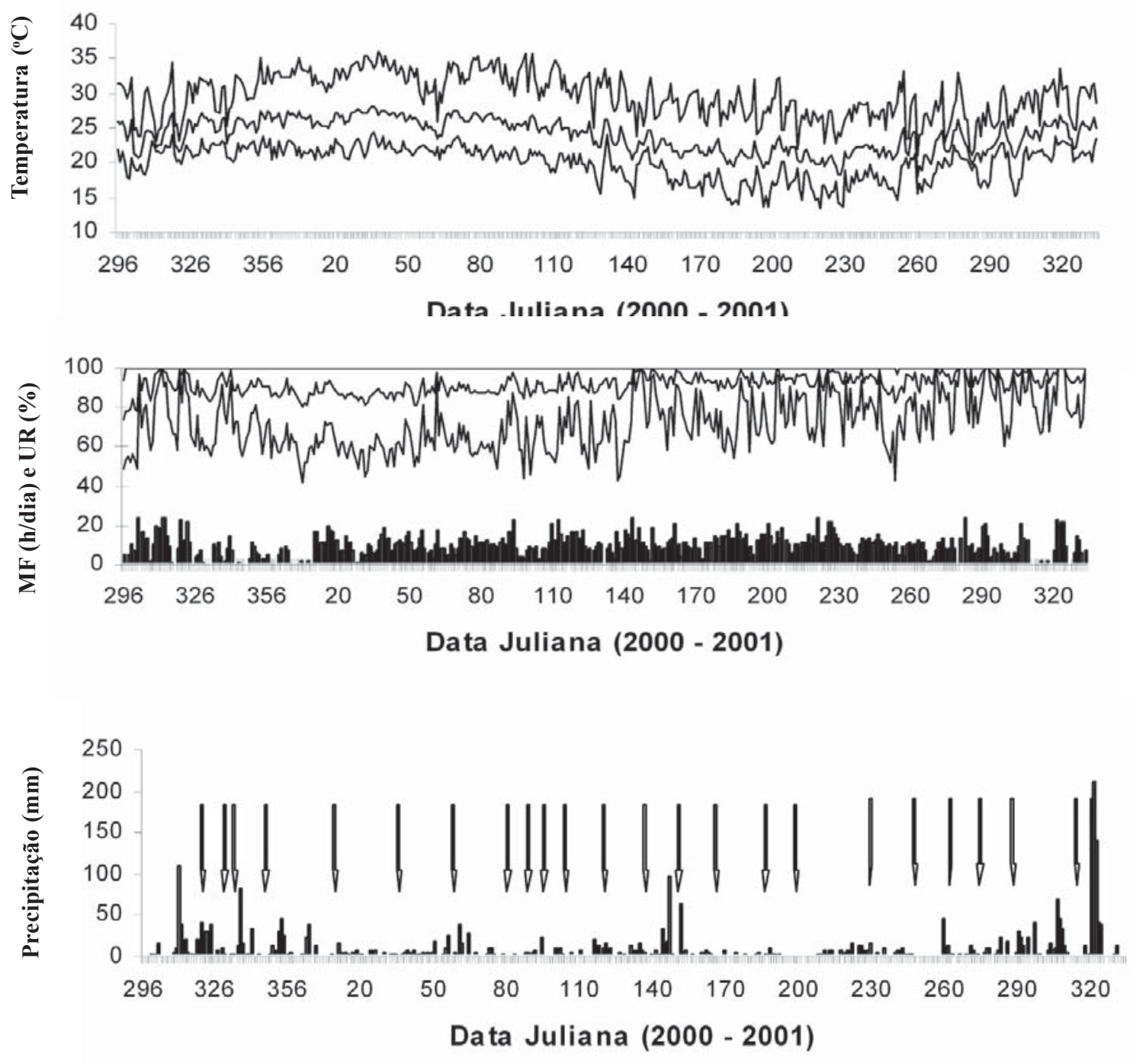

Figura 4 - Dados meteorológicos da Fazenda Lagoa do Macuco (Macuco). A) Temperaturas máxima, média e mínima; B) horas com molhamento foliar (MF) - barras -, e umidade relativa do ar (UR) - linhas; C) precipitação - as setas indicam os dias das pulverizações com fungicidas na área Curral.

pinta-preta. A severidade da doença, na área onde as plantas foram irrigadas pelo método de aspersão, foi maior do que nas áreas 1 e 3 (irrigação por gotejamento e microaspersão, respectivamente), variando de 1,0 a 6,8; 0,1 a 3,8, e 0,4 a 1,5 nas áreas 2, 1 e 3, respectivamente. A baixa severidade detectada e a ausência de ocorrência da doença na maior parte das épocas de avaliação impedem a confirmação de quais fatores climáticos poderiam estar diretamente envolvidos na predisposição das epidemias dessa doença. Sugere-se que sejam realizados maiores estudos por períodos mais longos e com lavouras com diferentes datas de plantio para determinar a existência da correlação da doença com fatores climáticos.

No caso do oídio, apesar da ocorrência de epidemias com altas taxas de progresso, não foi detectado amarelecimento intenso, nem desfolha, nas áreas de estudo (18). A faixa de temperatura com maiores correlações com a severidade da doença esteve entre 15 a $20^{\circ} \mathrm{C}$ (r igual a 0,$85 ; 0,88 ; 0,85 ; 0,77$; e 0,70 para Santa Terezinha 10 , testemunha com sanitização, sem sanitização, curral e Bitchisner, respectivamente), sendo a umidade relativa de 60 a $70 \%$ a que apresentou as maiores correlações $(0,59 ; 0,62 ; 0,64 ; 0,69$; e 0,66 para a Santa Terezinha 10 , testemunha com sanitização, sem sanitização, curral e Bitchisner, respectivamente).

Em relação às doenças em frutos, analisadas em pós-colheita, verificou-se correlação com a precipitação pluvial acumulada nos $15 \mathrm{e}$ 150 dias anteriores à colheita (Figuras 3 e 6). A temperatura favorável foi 25 a $30^{\circ} \mathrm{C}$ e a umidade relativa favorável foi maior do que $80 \%(14,23)$.

Não se observou relação entre incidência da podridão-peduncular e a precipitação pluvial acumulada 15 dias antes da avaliação ou no período de desenvolvimento do fruto ( $\mathrm{r}$ sempre abaixo de 0,21 não significativo). No caso da antracnose e da mancha-chocolate, não foi possível obter correlação significativa da incidência da doença com as condições climáticas $(12,16)$. Esses autores também não observaram correlação entre a precipitação acumulada e os valores de horários 
A

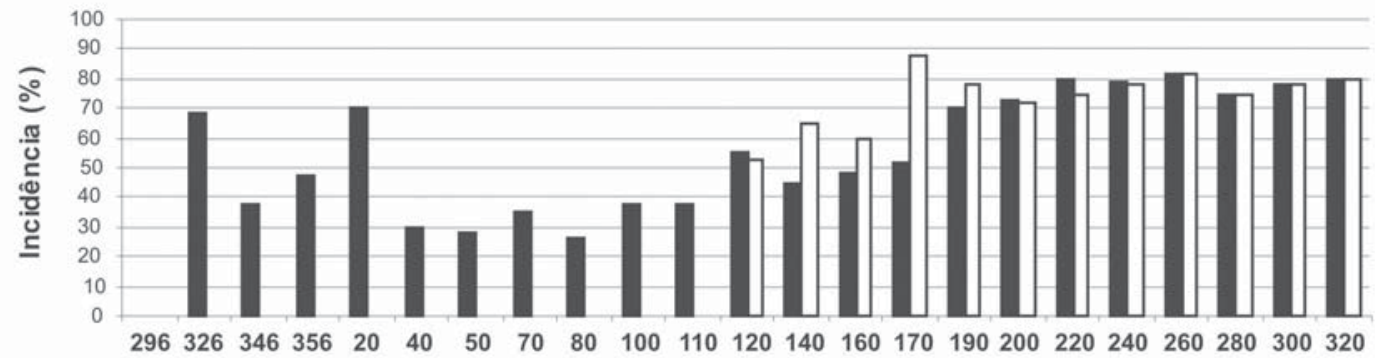

B

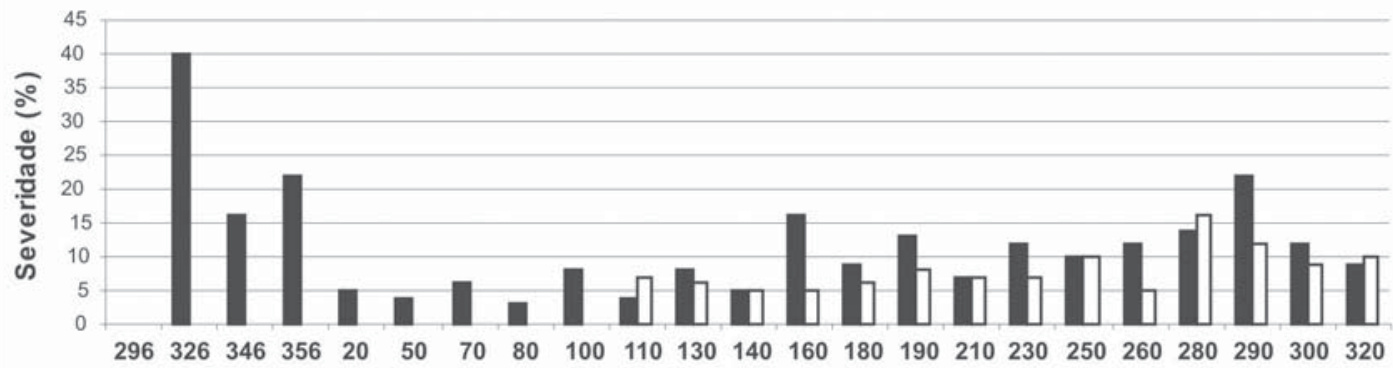

C

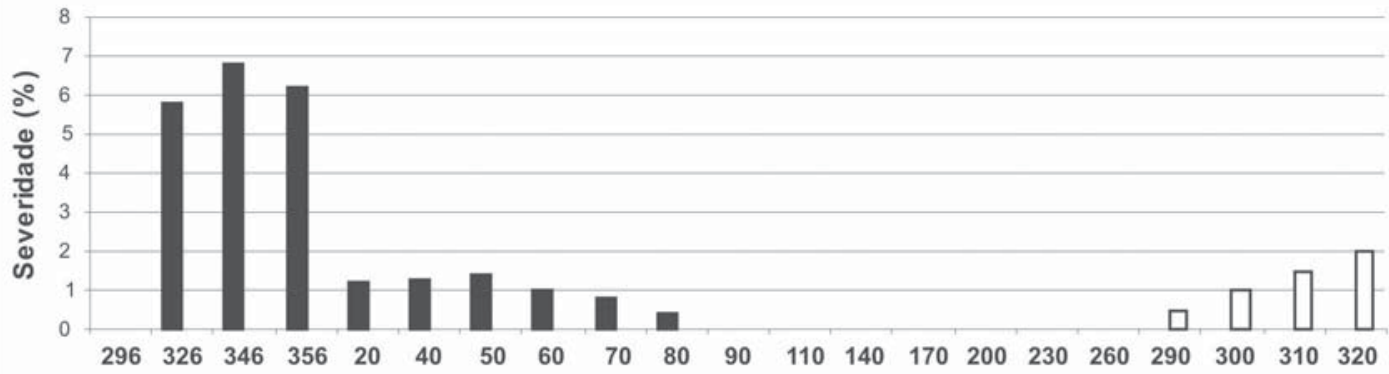

D

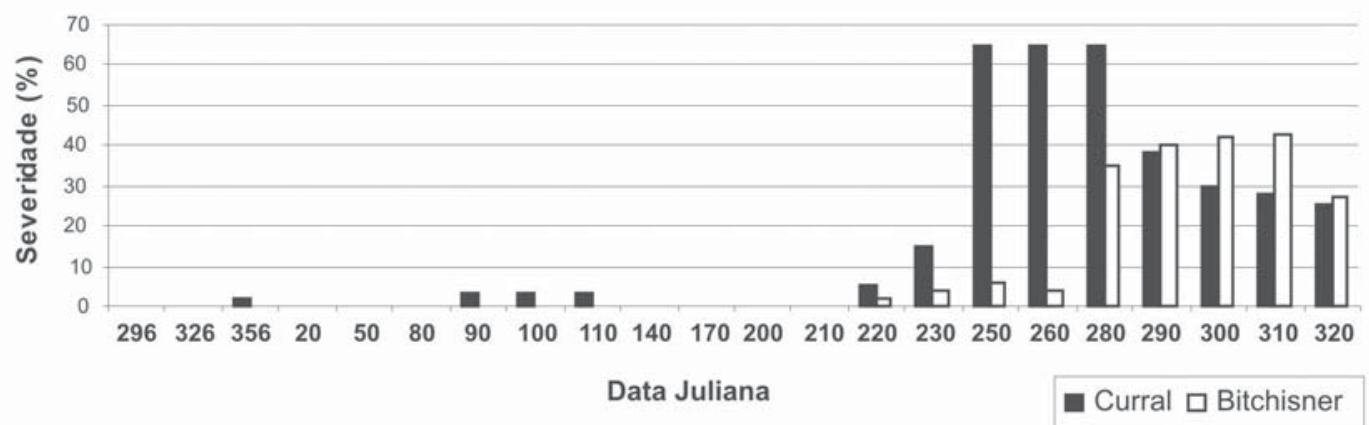

Figura 5 - Incidência de folhas doentes (A) e severidade de mancha-de-ascoquita (B), pinta-preta (C) e oídio (D). Os dados meteorológicos para ambas as áreas são provenientes da estação instalada na área Curral. 
A

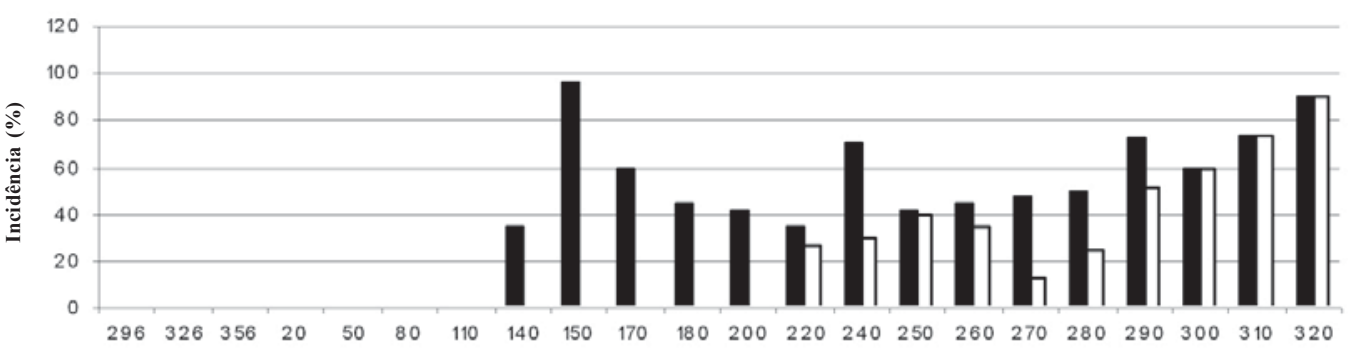

B

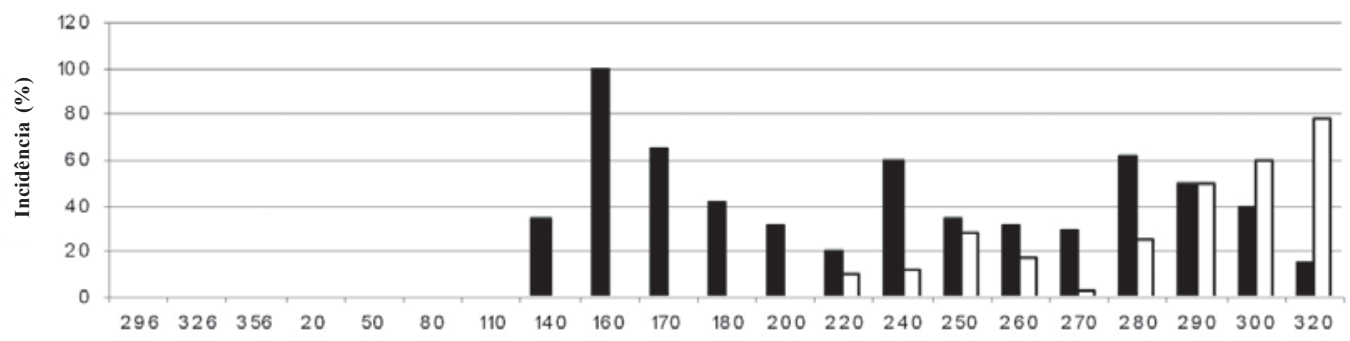

C

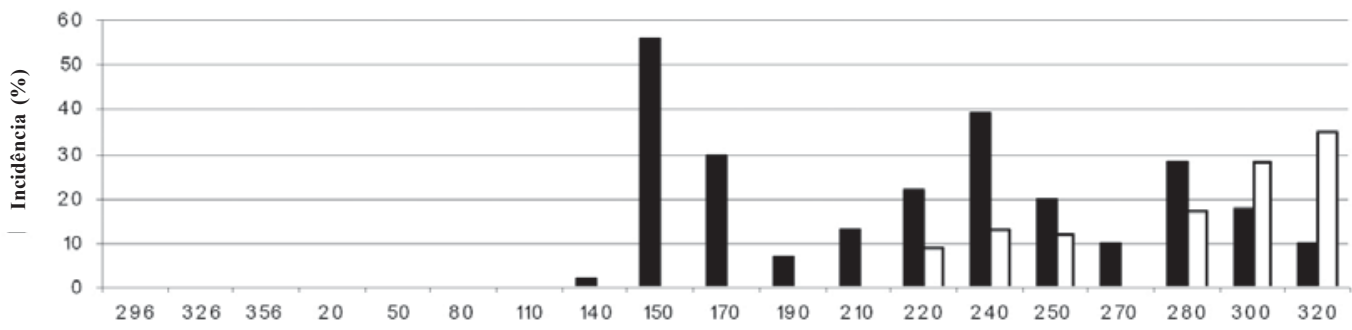

D

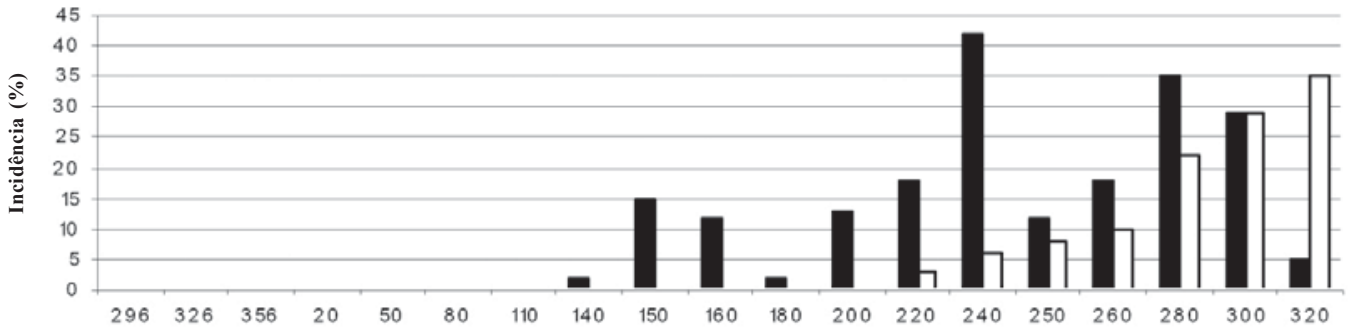

$\mathrm{E}$

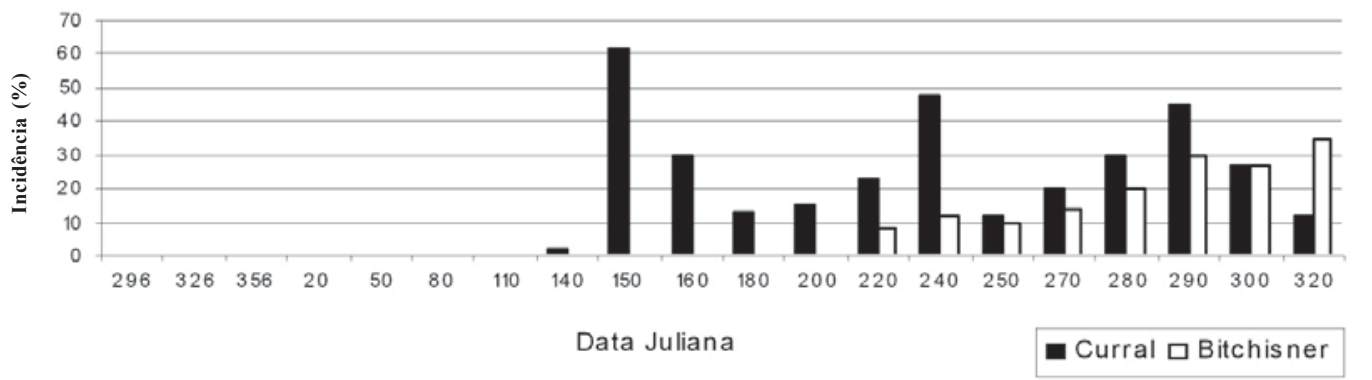

Figura 6 - Incidência das principais doenças de frutos detectadas nas Áreas 2 e 3. (A-Frutos doentes totais; B-Podridão penducular; C-Antracnose; D-Mancha chocolate; E-Antracnose e ou Mancha chocolate). 
Tabela 1- Incidência de frutos doentes em pós-colheita em função de práticas culturais na cultura do mamoeiro.

\begin{tabular}{|c|c|c|c|c|c|c|c|c|}
\hline Tratamento & \multicolumn{2}{|c|}{ Fru. Doe. Tot. ${ }^{1}$} & \multicolumn{2}{|c|}{ Pod.Ped. ${ }^{2}$} & \multicolumn{2}{|l|}{ Ant. $^{3}$} & \multicolumn{2}{|c|}{ Man $\mathrm{Cho}^{4}$} \\
\hline Padrão produtor & $30,5 a^{*}$ & $15,5 \mathrm{a}$ & $26,4 \mathrm{a}$ & $27,4 \mathrm{a}$ & $12,2 \mathrm{a}$ & $4,6 \mathrm{a}$ & $6,3 \mathrm{a}$ & $2,5 \mathrm{a}$ \\
\hline Sem sanitização & $92,0 \mathrm{~b}$ & $79,8 b$ & $87,8 \mathrm{~b}$ & $78,3 b$ & $75,5 \mathrm{~b}$ & $77,9 \mathrm{~b}$ & $70,5 \mathrm{~b}$ & $57,7 \mathrm{~b}$ \\
\hline $\mathrm{CV}(\%)$ & 12,5 & 14,8 & 13,9 & 16,3 & 14,7 & 13,5 & 15,3 & 13,8 \\
\hline
\end{tabular}

1-Incidência de frutos doentes totais (com podridão); 2-Incidência de frutos com podridão peduncular; 3-Incidência de frutos com antracnose; 4Incidência de frutos com mancha-chocolate; 5-Data Juliana de coleta dos frutos no campo; 6-Data Juliana de coleta dos frutos no campo.

*Médias seguidas pelas mesmas letras nas colunas não diferem entre si pelo teste de Tukey a $5 \%$.

com umidade relativa e temperatura favoráveis às doenças (temperatura entre 25 e $32{ }^{\circ} \mathrm{C}$ e umidade relativa acima de $80 \%$ ) e a incidência de doenças pós-colheita. $\mathrm{Na}$ área 1 , na testemunha sem sanitização, na data juliana 192 e 205, a incidência de antracnose foi de 65,4 e 57,1\%, nessa ordem, sendo a precipitação acumulada nos 15 dias anteriores à colheita de 26,8 e $1,4 \mathrm{~mm}$, respectivamente. Outros dados como esses, também podem ser observados para a data de 268 e 283 , para o tratamento padrão do produtor; 192 e 205 , para a testemunha com sanitização; e 246 e 272 para a área do curral. Entretanto, na prática, no norte do Estado do Espírito Santo, tem-se observado elevada incidência devido ao fato de a principal fonte de inóculo no pomar, ser lesões em folhas senescentes $(11,16)$. Os conídios, produzidos em acérvulos, são dispersos principalmente por respingos de chuva para outras áreas e outros frutos. Essa época coincide com a maior produção de frutos no norte do Estado. Em períodos secos e de temperaturas baixas, ocorre menor intensidade da doença, mas há grande possibilidade de ocorrência de epidemias, uma vez que, ocorre a liberação de ascósporos, os quais não necessitam de água para a dispersão (16). No Havaí, foi observado que, durante os meses de inverno, a abundância de ascósporos de Gomerella cingulata (forma perfeita de Colletotrichum gloesosporioides) capturados, esteve associada à alta incidência da doença nos frutos (14). A recente detecção da forma perfeita do patógeno da antracnose, Glomerella cingulata (Ston.) Spauld. \& Schrenk, em pomares de mamão no município de Linhares, Espírito Santo, pode alterar as características de epidemias da doença (8). Portanto ao invés de se tentar correlacionar a incidência de doenças em frutos com a precipitação acumulada, deve-se realizar futuros estudos, tentando correlacionar a incidência das doenças com a precipitação acumulada e a sua intensidade $\left(\mathrm{mm} \cdot \mathrm{h}^{-1}\right)$. É de se esperar que um mesmo volume de chuva em uma única hora, pode ser mais prejudicial às epidemias, devido ao escorrimento do inóculo, do que esse mesmo volume de chuva distribuído por várias horas. Deve-se estudar a influência desses fatores no período de duas semanas e 150 dias $(2,16)$ que antecedem a colheita, pois existe forte evidência de que a infecção na fase final do desenvolvimento do fruto (uma ou duas semanas antes da colheita) determina a intensidade de antracnose póscolheita.

Quanto ao progresso das doenças estudadas na área de Santa Terezinha 10 (Figura 2), a mancha-de-ascochyta foi constatada em todas as épocas de avaliação, tendo severidade máxima na data 155 aos 250 dias e mínima dos 20 aos 80 dias; a pinta-preta progrediu na data 326 aos 70 dias com severidade máxima na data 336 dias, e o oidio progrediu em duas épocas distintas sendo uma na data 330 aos 80 dias e a outra na data 240 aos 320 dias com o máximo na data 240 a 250 dias. A podridão dos frutos em pós-colheita foi detectada na data 140 aos 320 dias, sendo alta até a data 220 e a partir daí decresceu até a data 320 (Figura 3). A incidência das podridões dos frutos em pós- colheita, não foi significativa entre os tratamentos culturais envolvendo a sanitização (remoção de folhas senescentes e doentes) e ausência de sanitização (Figura 3, Tabela 1). O tratamento padrão praticado pelo produtor diferiu significativamente dos tratamentos envolvendo práticas culturais com e sem sanitização, excetuando a podridão peduncular onde o tratamento padrão igualou-se ao tratamento com sanitização (Tabela 1). No tratamento padrão, aplicações de fungicidas foram empregadas regularmente para o controle das doenças foliares e das podridões dos frutos, mas sem a remoção de folhas senescentes e doentes. No tratamento com sanitização, somente foram removidas folhas senescentes e doentes (mancha-de-ascoquita, pinta-preta, antracnose, mancha-de-Cladosporium) posicionadas no terço inferior da planta. Entretanto, comparando-se os tratamentos com sanitização e sem sanitização para podridão peduncular houve ganhos de $24 \%$ e $9 \%$, para as datas julianas 170 e 210 , respectivamente; para a antracnose houve ganhos de $13 \%$ e $55 \%$, para as datas julianas 160 e 230 , respectivamente e para a mancha-chocolate $30 \%$ e $9 \%$, para as datas julianas 170 e 210 , respectivamente. Portanto, embora os dois tratamentos culturais não diferissem entre si, há que se considerar a fonte de inóculo em folhas senescentes, tanto de Ascochyta caricapapayae agente causal da mancha-de-ascoquita e Asperisporium caricae agente causal da pinta-preta e outros fungos que incidem nas folhas do mamoeiro que podem servir de fonte de inóculo para os frutos como Phoma carica-papayae, Colletotrichum gloeosporioides e Cladosporium sp., Phomopsis sp. e Fusarium sp.(1, 4, 5, 6, 15, 17, $23,24)$. Este é o primeiro relato da importância da remoção de folhas doentes e senescentes de mamoeiro, visando redução de inóculo para os frutos e folhas novas.

O progresso das doenças nas áreas de plantio do curral e Bitchisner foram quase idênticas com relação à incidência de folhas doentes total, excetuando-se nas datas 160-170, onde as plantas da localidade Bitchisner atingiram $87 \%$ de incidência e as plantas do curral cerca de $60 \%$; a severidade máxima da mancha-de-ascoquita atingiu $20 \%$ na área do curral e $10 \%$ na área Bitchisner entre as datas 110 e 320 (Figura 5). A mancha-de-ascoquita é uma doença que incide no mamoeiro durante o ano todo, sempre nas folhas inferiores da planta e como se manifesta geralmente em folhas senescentes, aparentemente não causa danos ao mamoeiro (17). A pinta-preta foi muito severa na lavoura do curral e de baixa severidade na lavoura Bitchisner. A lavoura do curral como é irrigada pelo método de aspersão, favoreceu a pinta-preta (Figura 4), pelo fato das folhas permanecerem molhadas por período de tempo maior do que as plantas da lavoura Bitchisner, onde a irrigação foi por microaspersão $(15,26)$. O oidio foi detectado nas duas lavouras nas datas 230 aos 320; entretanto a severidade foi maior na lavoura do curral onde predomina a irrigação por aspersão. Obtêve-se severidade de Oidio máxima de 45 e $65 \%$ nas lavouras do curral e Bitchisner, respectivamente. A irrigação por aspersão, provavelmente, disseminou 
os conídios do fungo Ovulariopsis papayae mais eficientemente nas plantas da localidade do curral do que o método da microaspersão nas plantas da localidade Bitchisner. Em se tratando da podridão dos frutos do mamoeiro (podridão peduncular, antracnose, mancha-chocolate), a incidência foi maior nas plantas da localidade curral do que Bitchisner; mais uma vez evidenciando que o método de irrigação por aspersão aumenta a intensidade da podridão dos frutos do mamoeiro em comparação ao método da microaspersão. A irrigação por aspersão, associada à estação das chuvas nos meses de novembro a março, época de frutificação das áreas em estudo, contribuiu para o aumento da podridão dos frutos do mamoeiro (Figuras 3 e 6). Portanto, é neste período que se devem concentrar as medidas mais intensamente no controle das podridões dos frutos do mamoeiro (26).

\section{AGRADECIMENTOS}

Os autores expressam seus agradecimentos a Caliman Agrícola S. A., que cedeu suas lavouras para a condução dos experimentos.

\section{REFERÊNCIAS BIBLIOGRÁFICAS}

1. Alvarez, A.M.; Nishijima, W.T. Postharvest diseases of papaya. Plant Disease, Saint Paul, v.71, n. 8, p.681-686, 1987.

2. Alvarez, A.M.; Hylin, J.W.; Ogata, J.N. Postharvest diseases of papaya reduced by biweekly orchard sprays. Plant Disease Reporter, Saint Paul, v.61, n.9, p.731-735, 1977.

3. Bergamin Filho, A.; Amorim, L. Doenças de plantas tropicais: epidemiologia e controle econômico. São Paulo: Ed. Agrnômica Ceres, 1996. 299 p.

4. Bergamin Filho, A.; Kimati, H. Doenças do mamoeiro (Carica papaya L.). In: Galli, F. (Coord.). Manual de fitopatologia. doenças das plantas cultivadas. 2. ed. São Paulo: Agronômica Ceres, 1980. v.2, p.339-346.

5. Bolkan, H.A.; Cupertino, F.P.; Dianese, J.C.; Takatsu, A. Fungi associated with pre-and postharvest fruit rots of papaya and their control in Central Brazil. Plant Disease Repórter, Saint Paul, v.60, n. 7, p.605-609, 1976.

6. Costa, H.; Ventura, J.A.; Rodrigues, C.H.; Tatagiba, J.S. Ocorrência e patogenicidade de Glomerella cingulata em mamão no Norte do Estado do Espírito Santo. Fitopatologia Brasileira, Fortaleza, v.26, n. 2, p.328, 2001. (Resumo).

7. Dickman, M.B.; Alvarez, A.M. Latent infection of papaya caused by Colletotrichum gloeosporioides. Plant Disease, Saint Paul, v.67, n. 7, p.748-750, 1983.

8. Dickman, M.B. Antracnose. In: Papaya diseases caused by fungi. In: Ploetz, R.C.; Zentmeyer, G.A.; Nishima, W.T.; Rohrbach, K.G.; Ohr, H.D. (Ed.). Compendium of tropical fruit disease. St. Paul. APS Press, 1994. 88p

9. Duran, A.; Mora, D.; Chavarria, E. Determinación de la edad susceptible del fruto de la papaya (Carica papaya L.) a la antracnosis (Colletotrichum gloeosporioides Penz.). Agronomía Mesoamericana, Mexico, v.10, n.1, p.1-6. 1999.

10. Duran, J.A.; Mora, D. Diagnostico de las enfermedades postcosecha de la papaya en Costa Rica. II. Cuantificacion y epidemiologia de las enfermedades del fruto. Agronomia Costarricense, San Jose, v.12, n.1, p.7-18, 1988

11. Elder, R.J.; MacLeod, W.N.B.; Bell, K.L.; Tyas. J.A.; Gillespie, R.L. Growth, yield and phenology of 2 hybrids papayas (Carica papaya L.) as influenced by method of water application. Australian Journal of Experimental Agriculture, Sidney, v.40, n. 8, p.739-746, 2000.

12. Gupta, A.K.; Pathak, V.N. Epidemiology and management of papaya fruit rots. Summa Phytopathologica, Botucatu, v.16, n.2, p.92105, 1990.

13. Horsfall, J.G.; Barrat, R.W. An improved grading system for measuring plant diseases. Phytopathology, Saint Paul, v.35, n. 8, p.655, 1945. Abstract.

14. Hunter, J.E.; Buddenhagen, I.W. Incidence, epidemiology and control of fruit diseases of papaya in Hawaii. Tropical Agriculture, Honolulu, v.49, n. 1, p.61-71, 1972.

15. Liberato , J.R.; Costa, H. Incidência de antracnose e podridão peduncular em frutos de mamoeiro em Linhares, ES. Fitopatologia Brasileira, Brasília, v.22, (supl.), p.276, 1997. (Resumo).

16. Liberato, J. R.; Barreto, R. W.; Rodrigues, C. H.; Costa, H. Ocorrência de oídio (Ovulariopsis) em mamoeiro no Estado do Espírito Santo. Fitopatologia Brasileira, v.29, (supl.), p.368, 1995. Resumo.

17. Liberato, J.R.; Zambolim, L. Controle das doenças causadas por fungos, bactérias e nematóides em mamoeiro. In: Zambolim, L.; Vale, F.X.R. do; Monteriro, A.J.A.; Costa, H. (Ed.). Controle de doenças de plantas: fruteiras. Viçosa: Suprema Gráfica e Editora, 2002. v.2, p.1023-1138.

18. Luna, J.V.U. Intervalo entre a polinização e maturação de cultivares de mamão (Carica papaya L.). Salvador, Empresa de Pesquisa Agropecuária da Bahia, 1979. 6p. (Comunicado Técnico, 19).

19. Marin, S.L.D.; Gomes, J.A.; Salgado, J.S.; Martins, D.S.; Fullin, E.A. Recomendações para a cultura do mamoeiro dos grupos Solo e Formosa no Estado do Espírito Santo. 4, Vitória: Empresa Capixaba de Pesquisa Agropecuária, 1995. 57 p. (Circular Técnica, n. 3).

20. Martins, D.S. Exportação de mamão 'Solo' para os Estados Unidos Procedimentos. In: Ritzinger, C.H.S.P.; Souza, J.S. Mamão: Fitossanidade. Brasília, DF: EMBRAPA, 2000. p.15-22.

21. Medina, J.C. Cultura. In: Mamão: cultura, matéria-prima, processamento e aspectos econômicos. 2. ed. Campinas, ITAL, 1989. p.1178.

22. Quimio, T.H. Temperature as factor for growth and sporulation of anthracnose organism of papaya. Philippine Agriculturist, Manilha, v.57, n. 3, p.245-253, 1973.

23. Rezende, J.A.M.; Fancelli, M. I. Doenças do mamoeiro (Carica papaya L.). In: Kimati, H.; Amorim, L.; Bergamin Filho, A.; Camargo, L.E.A.; Rezende, J.A.M. (Ed.). Manual de fitopatologia. doenças das plantas cultivadas. 3. ed. São Paulo: Agronômica Ceres, 1997. v. 2, p.486-496.

24. Stevens, H.E. Papaya diseases. Proceedings of the Florida State Horticultural Society, Gainesville, v.52, n. 1, p.57-63, 1939.

25. Tatagiba, J. S.; Liberato, J. R.; Zambolim, L.; Costa, H.; Ventura, J. A. Controle químico do oídio do mamoeiro. Fitopatologia Brasileira, Fortaleza, v.27, n. 3, p.219-222, 2002.

26. Tatagiba, J. S.; Liberato, J. R.; Zambolim, L.; Ventura, J. A.; Costa, H. Controle e condições climáticas favoráveis à antracnose do mamoeiro. Fitopatologia Brasileira, Fortaleza, v.27, n. 2, p.186-192, 2002. 